\title{
Análise da situação epidemiológica do novo coronavírus no município de Jataí, Goiás
}

\author{
Izadora Rodrigues da Cunha ${ }^{1}$ \\ Felipe Coutinho Rodrigues ${ }^{2}$ \\ Ana Elisa Pereira Braga ${ }^{3}$ \\ Bruna Fernandes da Silva ${ }^{4}$ \\ Marina Isabela de Paula Sousa ${ }^{5}$ \\ Ana Amélia Freitas-Vilela ${ }^{6}$
}

\begin{abstract}
RESUMO:
O contexto epidemiológico vivenciado no município de Jataí reflete a epidemia da COVID-19, não somente no estado de Goiás, mas em todo o país. Inúmeros protocolos foram utilizados como medidas preventivas na tentativa de conter a COVID-19 no município, seguindo as recomendações do governo estadual. Algumas situações levantadas no artigo podem ter interferido na curva epidemiológica da doença, como as eleições, feriados que resultaram em diminuição do isolamento social, decretos de abertura do comércio e a mudança da gestão municipal de 2020 a 2021. Todas essas questões foram levantadas e abordadas no presente artigo e analisadas de acordo com as literaturas disponíveis. Pensando num possível cenário de retorno de atividades presenciais na Universidade Federal de Jataí, os prováveis cenários devem ser analisados de acordo com o contexto e a curva epidemiológica da doença, para que possíveis previsões sejam realizadas e para que o delineamento dessa doença seja o mais próximo possível do esperado.

Palavras-chave: Pandemia. COVID-19. Saúde Pública.

\section{Analysis of the epidemiological situation of the new coronavirus in the municipality of Jataí, Goiás}

\begin{abstract}
:
The epidemiological context experienced in the municipality of Jataí mirrors the epidemic of COVID-19 not only in the state of Goiás, but throughout the country. Numerous protocols were used as preventive measures in an attempt to contain COVID-19 in the municipality, following the recommendations of the state government. Some situations raised in the article may have interfered in the epidemic curve, such as the elections, holidays that resulted in a social isolation decrease, commerce reopening decrees and the municipalities administrative change from 2020 to 2021. All these issues were raised and addressed in this paper and analyzed according to available literature. Thinking about a possible scenario of the resumption of presential activities at the Federal University of Jataí, the probable scenarios should be analyzed according to the context and epidemic curve, so that possible predictions are made and the delineation of this disease is as close as possible to what is expected.
\end{abstract}

Keywords: Pandemic. COVID-19. Public Health.

\footnotetext{
${ }^{1}$ Acadêmica de Medicina na Universidade Federal de Jataí (UFJ). E-mail: izadoracunha@ discente.ufj.edu.br

2 Acadêmico de Medicina na Universidade Federal de Jataí (UFJ). E-mail: felipecoutinho@ discente.ufj.edu.br

3 Acadêmica de Medicina na Universidade Federal de Jataí (UFJ). E-mail: anaelisa_0@ discente.ufj.edu.br

${ }^{4}$ Acadêmica de Medicina na Universidade Federal de Jataí (UFJ). E-mail: brunafs@ discente.ufj.edu.br

${ }^{5}$ Acadêmica de Medicina na Universidade Federal de Jataí (UFJ). E-mail: marinaisabela@ discente.ufj.edu.br

${ }^{6}$ Docente do curso de Medicina na Universidade Federal de Jataí (UFJ), doutora em Nutrição. E-mail: anaameliafv@ufj.edu.br
} 


\section{INTRODUÇÃO}

No dia 31 de dezembro de 2019, a Organização Mundial de Saúde (OMS) recebeu as primeiras notificações de casos de pneumonia, de etiologia até então desconhecida, na cidade Wuhan na China, que no dia 7 de janeiro de 2020. Foi anunciado que o agente etiológico do surto nessa cidade pertencia a uma cepa da família viral coronavírus $(\mathrm{CoV})$ que, como os demais vírus de mesma família, causava a Síndrome Respiratória Aguda Grave (SARS-CoV). A evolução do contágio viral, com 118.319 casos confirmado no mundo até 11 de março de 2020, levou a OMS a declarar que essa doença, conhecida agora como a doença de coronavírus 2019 (COVID-19, do inglês coronavírus disease), estava em estado de pandemia, momento em que o Brasil possuía 34 casos confirmados sem transmissão local (WHO, 2020).

As transmissão da COVID-19 ocorre principalmente por meio de gotículas respiratórias produzidas por uma pessoa infectada, e pelo contato direto com portadores do vírus ou por objetos já contaminados. Ademais, pessoas infectadas podem apresentar um período médio de incubação de 5 dias, mas esse intervalo entre contágio e apresentação de sintomas pode chegar a até 16 dias. O quadro sintomático desenvolvido pela COVID-19 é em maioria brando e algumas pessoas infectadas podem ainda ser assintomáticas, no entanto, observa-se que em alguns casos, pessoas infectadas podem apresentar uma sintomatologia grave, necessitando de hospitalização e até suporte respiratório (CHAN et al, 2020; GHINAI et al., 2020; BAI et al., 2020; LEE, et al, 2021).

A situação epidemiológica em Goiás acompanhava o mesmo caminho, sendo que no dia 12 de março de 2020, o estado de Goiás confirmava os primeiros 3 novos casos da doença, sendo declarada no dia seguinte, pelo Decreto 9633/2020 do Governo do Estado de Goiás, a emergência na saúde pública de Goiás. Nesse sentido, seguindo a Nota Técnica n ${ }^{\circ} 1 / 2020$ da Secretaria Estadual de Saúde (SES)-GO, o Conselho Universitário da Universidade Federal de Jataí suspendeu o calendário acadêmico 2020 dos cursos de graduação e de pós-graduação. Não demorou para que casos da doença fossem registrados no município de Jataí. Em 18 de março de 2020 foi diagnosticado o primeiro caso de COVID-19 no município, mas ainda sem ter havido a caracterização de transmissão comunitária (SES-GO, 2020).

Diante desse cenário, surgiu a preocupação acerca da velocidade de contágio e a proporção em escala mundial que essa doença atingiu, - disseminando-se até em países com sistema de saúde resiliente -bem como pela letalidade e a sobrecarga dos sistemas de saúde. Associado a esses fatores, a ausência de vacinas e de um tratamento eficaz, levou a criação de planos de contingência pelo governo federal e pelos governos estaduais, todos seguindo as 
orientações da OMS que determinaram a limitação de pessoas em ambientes fechados, entrada de um membro por família em supermercados, parques e praças interditados, distanciamento de no mínimo um metro entre uma pessoa e outra em filas de lotéricas, bancos e demais estabelecimentos, fechamento intercalado do comércio, venda de bebidas alcoólicas proibidas após um determinado horário e uso de álcool em gel ao entrar em bares, restaurantes, lojas e demais ambientes. Além disso, a nova variante P1 do Sars-Cov-2 já circula no Brasil e esta, com maior capacidade de transmissão e de letalidade impõe um maior risco de morbidade, agravos e morte. Devido a essa nova variante, as notificações de agravo têm crescido exponencialmente, juntamente com a escassez de recursos humanos, de insumos farmacológicos e de material de apoio (Comitê Extraordinário de Monitoramento Covid-19, 2021; NAVECA, et al, 2021).

A COVID-19 alterou a rotina da população do município de Jataí, inclusive a comunidade acadêmica da Universidade Federal de Jataí-UFJ, impossibilitando a realização de suas atividades. Assim, este estudo teve como objetivo analisar a situação epidemiológica da COVID-19 no município de Jataí desde o início da pandemia até os dias atuais avaliando os dias posteriores a feriados nacionais.

\section{METODOLOGIA}

Os dados coletados neste estudo foram obtidos dos sistemas de informação da Secretaria de Saúde da Prefeitura de Jataí, e da Superintendência de Vigilância em Saúde, disponíveis no site eletrônico da prefeitura (www.jatai.go.gov.br), portanto, a coleta foi realizada de forma secundária. Todas as informações enquadraram-se nos dispositivos da Lei de Acesso à Informação (Brasil, 2011), classificadas como informação pública.

A tabulação foi realizada no Excel Microsoft 365®, de acordo com a relevância das informações presentes nos Boletins Eletrônicos informados pela Secretaria de Saúde, como: casos confirmados, óbitos, letalidade, incidência por 1 mil habitantes, mortalidade por 1 mil habitantes, ocupação de leitos de enfermaria no Sistema Único de Saúde (SUS) e a sua taxa correspondente, ocupação de leitos de UTI disponibilizadas no SUS e sua taxa correspondente. Esses dados foram selecionados datados quinzenalmente, sendo então calculado o número de casos aumentados com a diferença de 15 dias.

Selecionou-se datas relevantes do ponto de vista epidemiológico que pudessem ter gerado aglomerações no município de Jataí para coleta de dados e análise. Realizou-se a tabulação dos dados - casos confirmados, óbitos, letalidade, incidência por 1 mil habitantes, 
mortalidade por 1 mil habitantes, ocupação de leitos de enfermaria no Sistema Único de Saúde (SUS) e a sua taxa correspondente, ocupação de leitos de UTI disponibilizadas no SUS e sua taxa correspondente - referentes ao período eleitoral municipal de primeiro turno - no dia 15 de novembro de 2020 - aos feriados de Natal - no dia 25 de dezembro de 2020 - ano novo - no dia 31 de dezembro de 2020 - de carnaval - nos dias 15 e 16 de fevereiro de 2021 - e Páscoa no dia 4 de abril de 2021. Para análise desses dados, foi calculada o aumento do número de casos nos seguintes 15 dias.

Não foi necessária a submissão do trabalho no Comitê de Ética em Pesquisa (CEP), uma vez que este estudo dispensa anuência do CEP pelo fato de que todos os dados utilizados apresentam-se como dados secundários, disponíveis para o acesso público.

\section{RESULTADOS}

Ao analisar os novos casos do município de Jataí, nota-se que os maiores aumentos ocorreram de março a julho de 2020, seguindo-se por um relativo período de queda até novembro do mesmo ano (Figura 1). Em 31 de julho de 2020, o Brasil registrou 1459 casos confirmados de COVID-19, acompanhado do maior registro quinzenal de novos casos de COVID-19 no município, registrando 877 novos casos da doença em duas semanas (Figura 1). O primeiro período de queda no registro de novos casos de COVID-19 foi observado em 15 de outubro de 2020, com registro de 212 novos casos quinzenais, até o dia 15 de novembro de 2020, com registro de 184 casos quinzenais. De novembro ao final de dezembro, o número de notificações de COVID-19 apresentou-se em alta, com registro de 615 casos semanais em 31 de dezembro de 2020. Esse aumento foi interrompido apenas no mês de janeiro de 2021

. De fevereiro a abril de 2021 observou-se aumento constante, maior ao observado nos primeiros meses de pandemia da COVID-19 no ano de 2020, com o maior número de novos casos quinzenais (931) registrado em 15 de março de 2021 (Figura 1). 
Figura 1:- Casos novos quinzenais de COVID-19 em Jataí-GO de 31 de março de 2020 a 14 de abril de 2021.

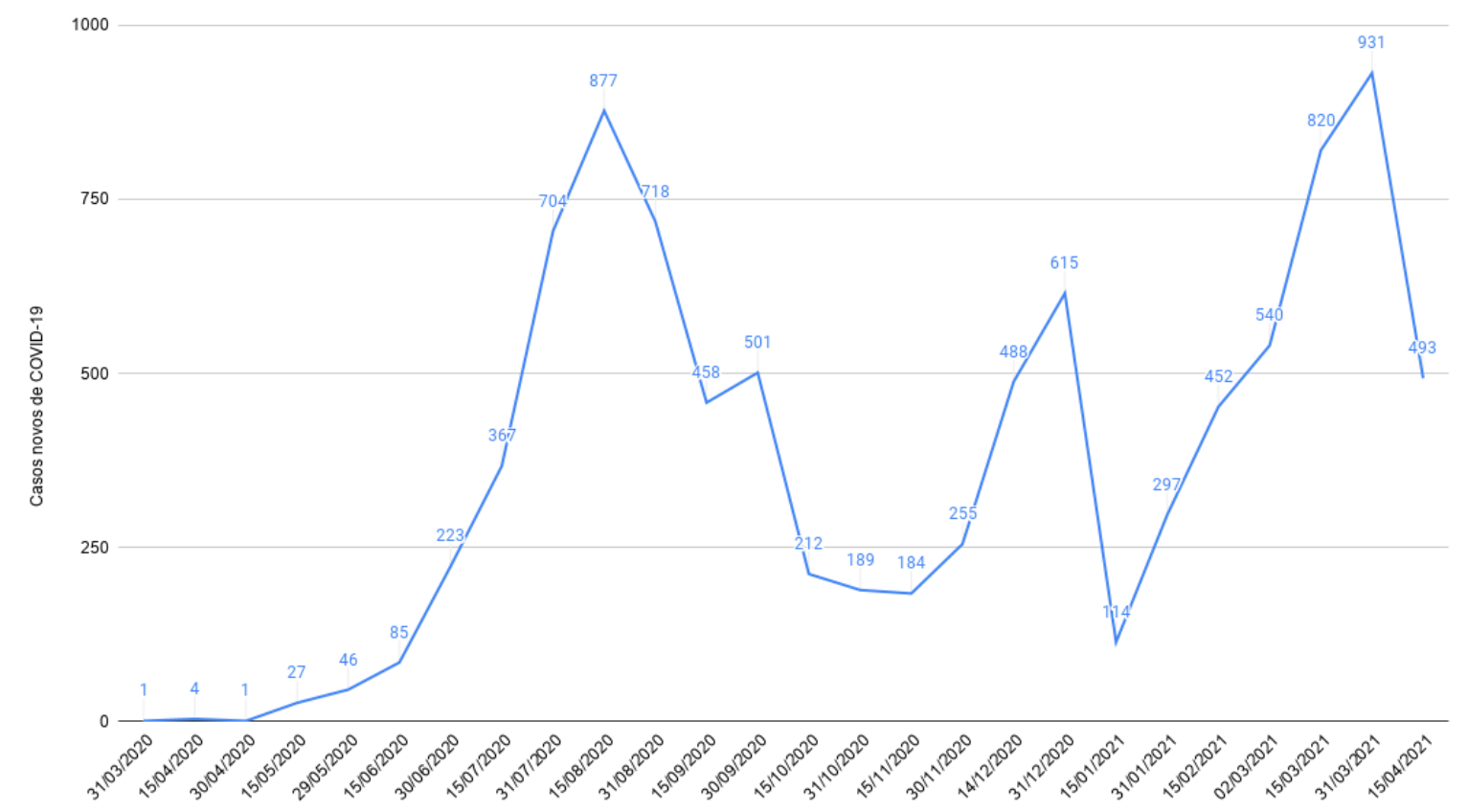

Fonte: Secretaria de Saúde de Jataí

Ao se analisar o calendário eleitoral (Figura 2) e o de datas comemorativas, como carnaval, que ocorreu em 16 de fevereiro de 2021 (Figura 3), notou -se que no período que antecedia em 15 dias essas datas, o número de novos casos confirmados era menor quando comparado a 15 dias posteriores, demonstrando uma possível relação entre o período eleitoral e de datas comemorativas com o maior aumento do número de casos de COVID-19 registrados. 
Figura 2: Casos confirmados de COVID-19 em Jataí-GO no período eleitoral.

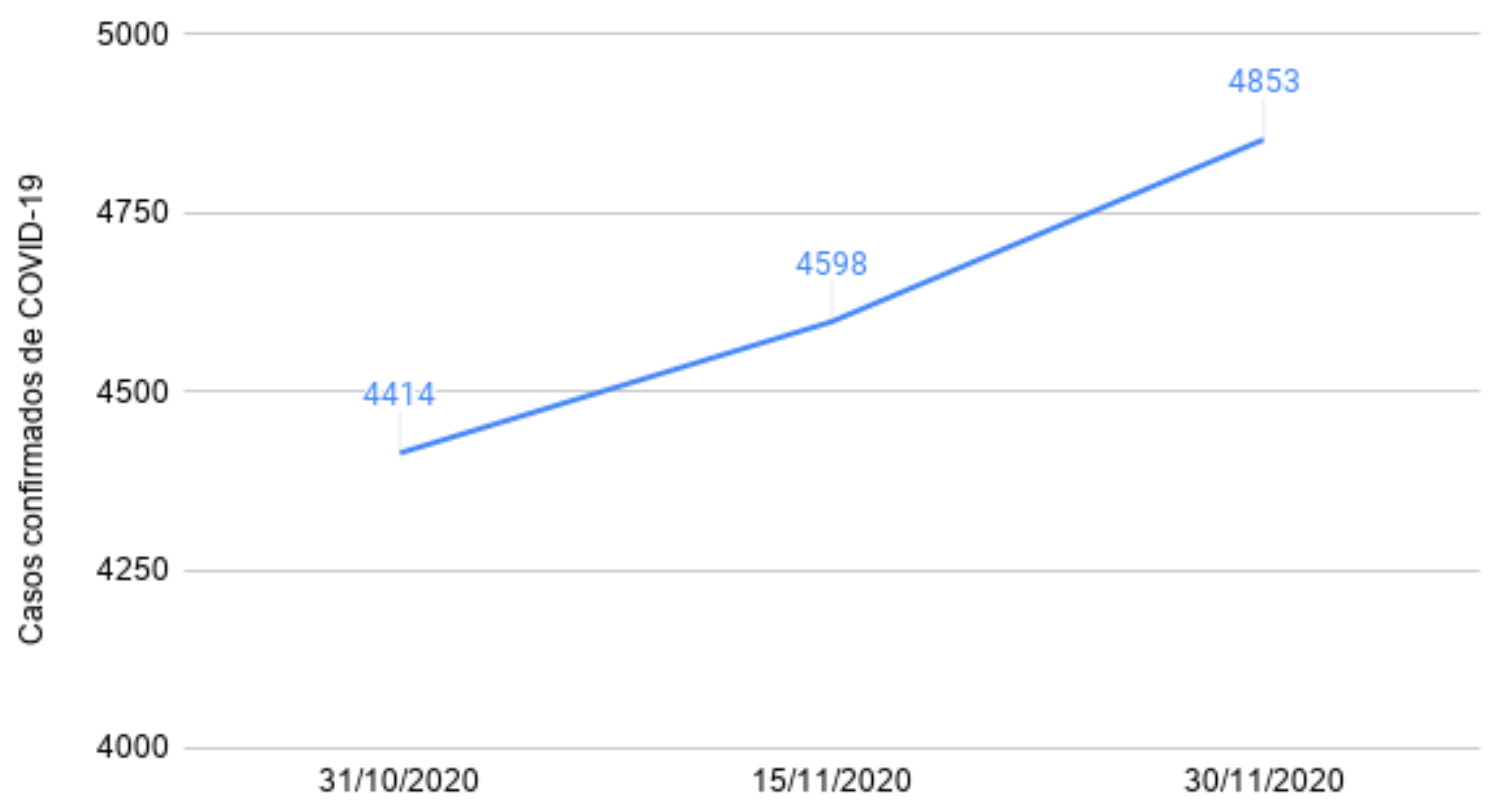

Fonte: Secretaria de Saúde de Jataí

Figura 3: Casos confirmados de COVID-19 em Jataí-GO no carnaval.

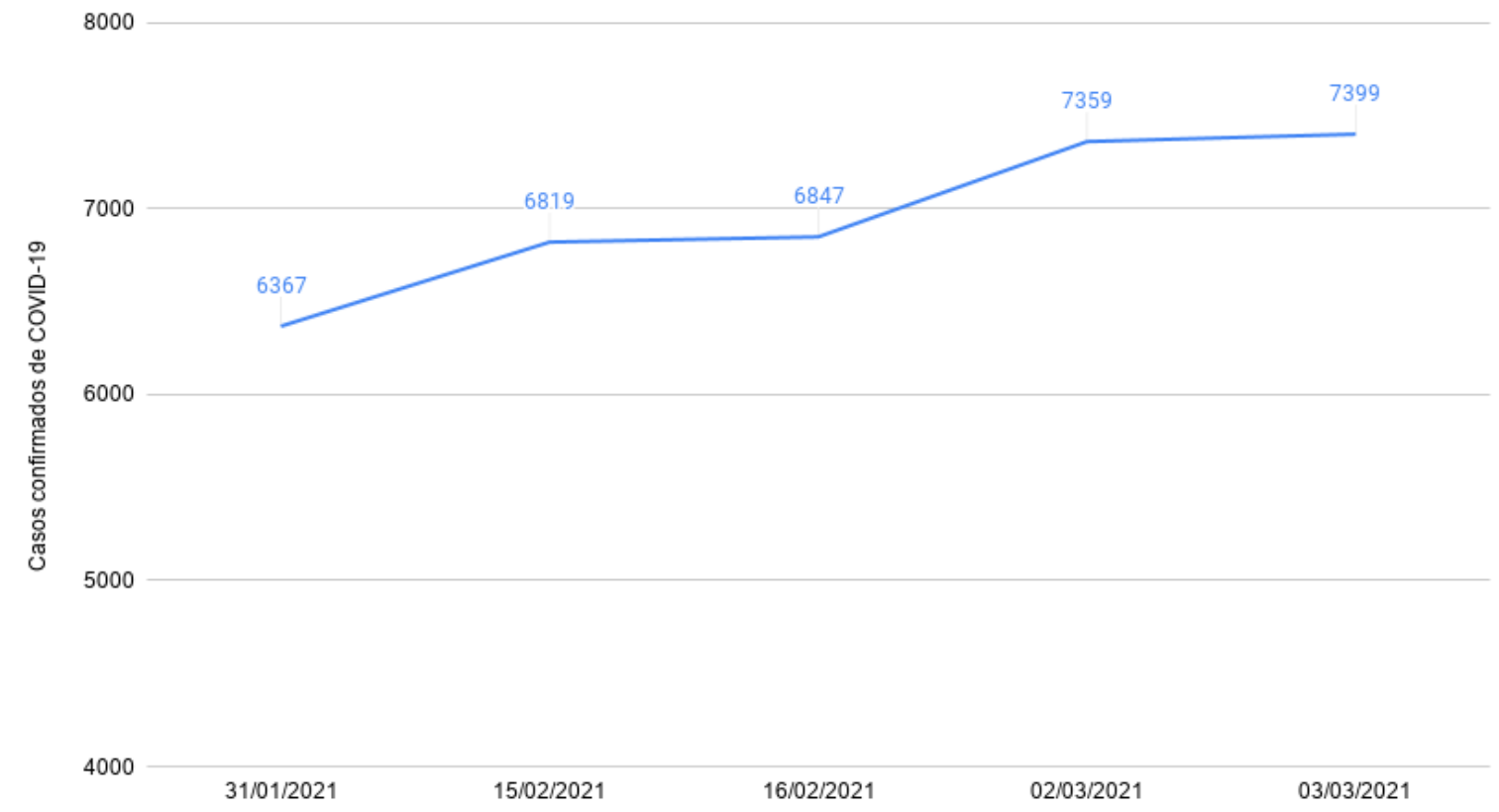

Fonte: Secretaria de Saúde de Jataí

Ao se comparar o percentual de aumento de casos notificados nos 15 dias anteriores ao primeiro turno das eleições (31 de outubro de 2021), observou-se que percentual era de 5,5\%, durante o primeiro turno das eleições (15 de novembro de 2020), 5,55\% no segundo e, após 15 
dias (30 de novembro de 2020), o percentual de aumento passou a ser de $10,06 \%$, evidenciando um aumento nos casos notificados de COVID-19 (Figura 4).

Figura 4: Percentual de aumento de novos casos de COVID-19 durante o período eleitoral.

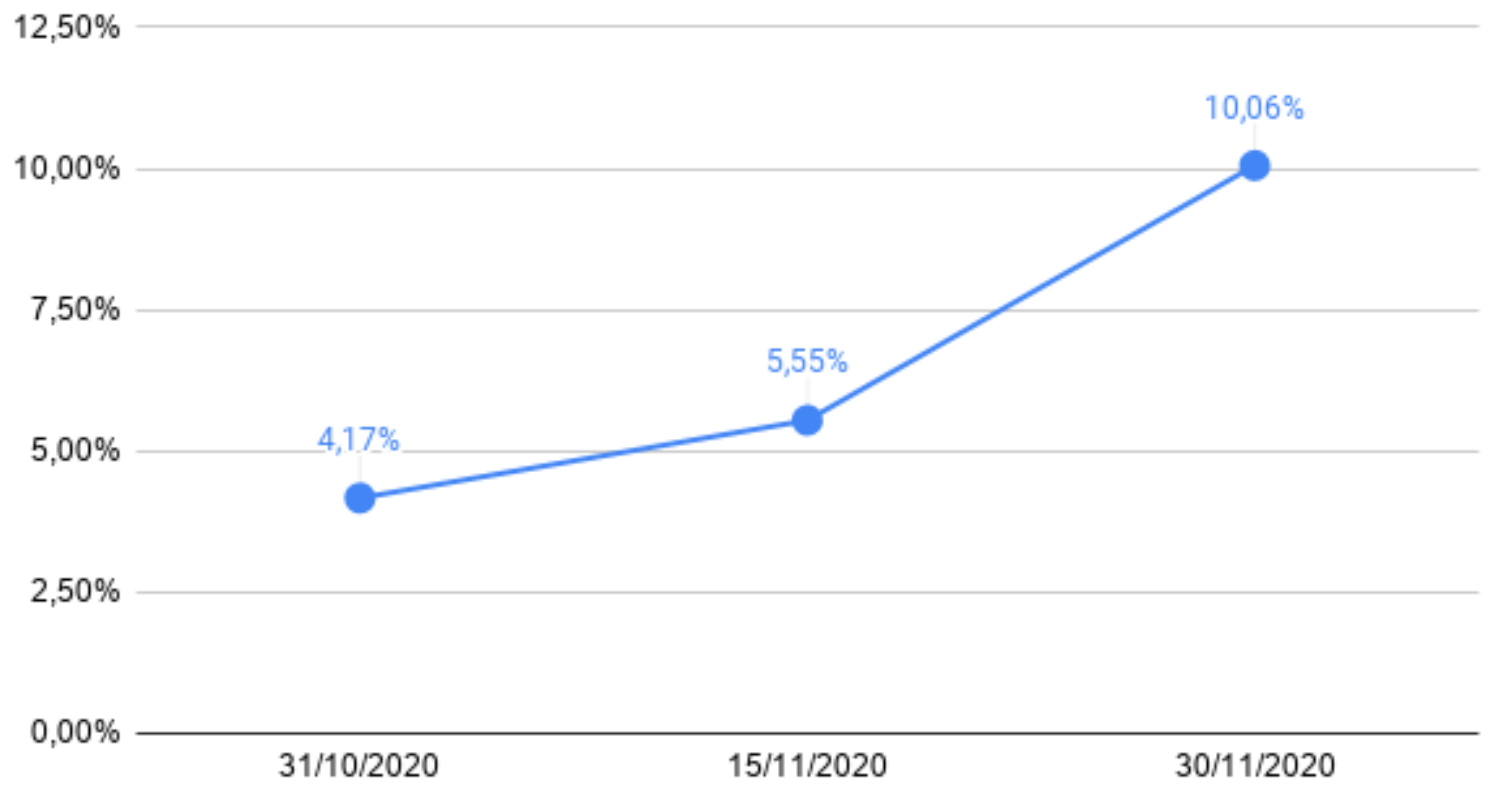

Fonte: Secretaria de Saúde de Jataí

Isso também pode ser observado no período referente ao carnaval ( 15 e 16 de fevereiro de 2021). No período anterior de 15 dias (31 de janeiro de 2021) o percentual de aumento dos casos notificados era de 7,10\%, no dia 15 e 16 de fevereiro de 2021, esse percentual era de $7,92 \%$ e 8,06\%, respectivamente. Nessa linha, 15 dias após o carnaval (2 e 3 de fevereiro de 2021), o percentual de aumento foi de $12,86 \%$ e 14,14\%, respectivamente (Figura 5). Isso evidencia a associação entre os feriados e o aumento de casos de COVID-19 na cidade de Jataí. 
Figura 5: Percentual de aumento de novos casos de COVID-19 durante o período de carnaval.

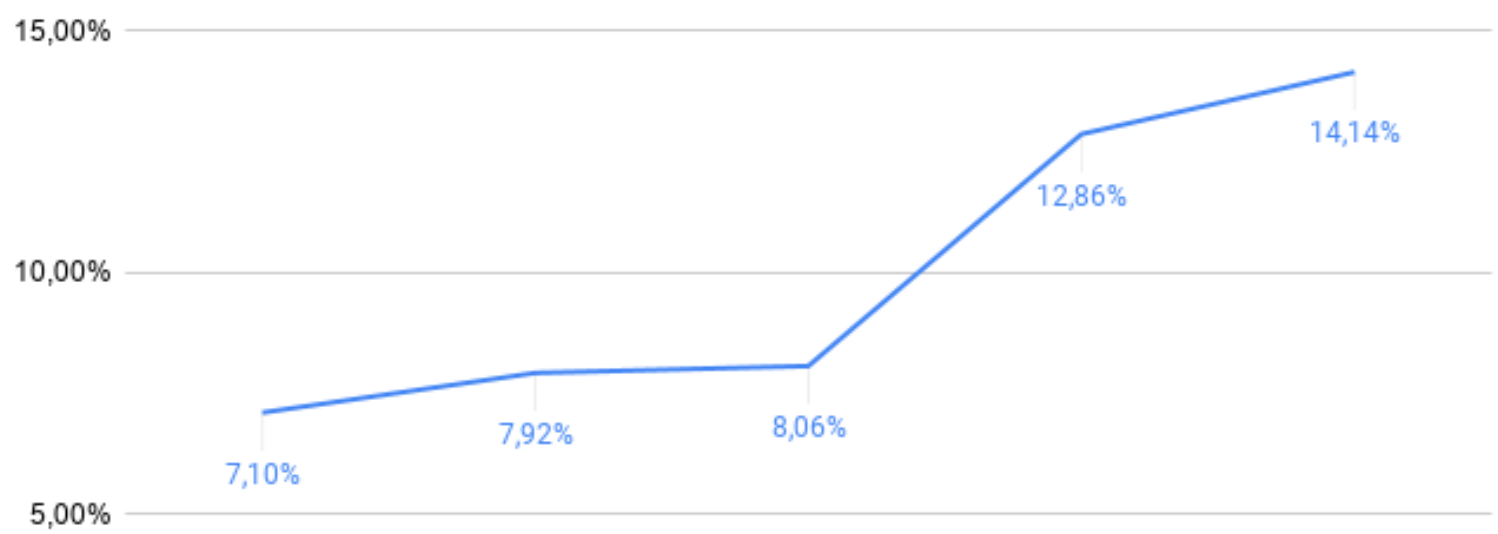

\begin{tabular}{|c|c|c|c|c|c|}
\hline & $31 / 01 / 2021$ & $15 / 02 / 2021$ & $16 / 02 / 2021$ & $02 / 03 / 2021$ & $03 / 03 / 2021$ \\
\hline
\end{tabular}

Fonte: Secretaria de Saúde de Jataí

No que se refere ao período de Natal e Ano Novo, não foi detectado um aumento significativo de casos, diferente dos observados no período eleitoral e no Carnaval de 2021. Entretanto, a análise das figuras 6 e 7, mostrou que, nos 15 dias posteriores aos feriados de fim de ano, houve um aumento dos casos de COVID-19.

Figura 6: Casos quinzenais confirmados de COVID-19 em Jataí-GO no período do Natal, Jataí 2020-2021. 7000

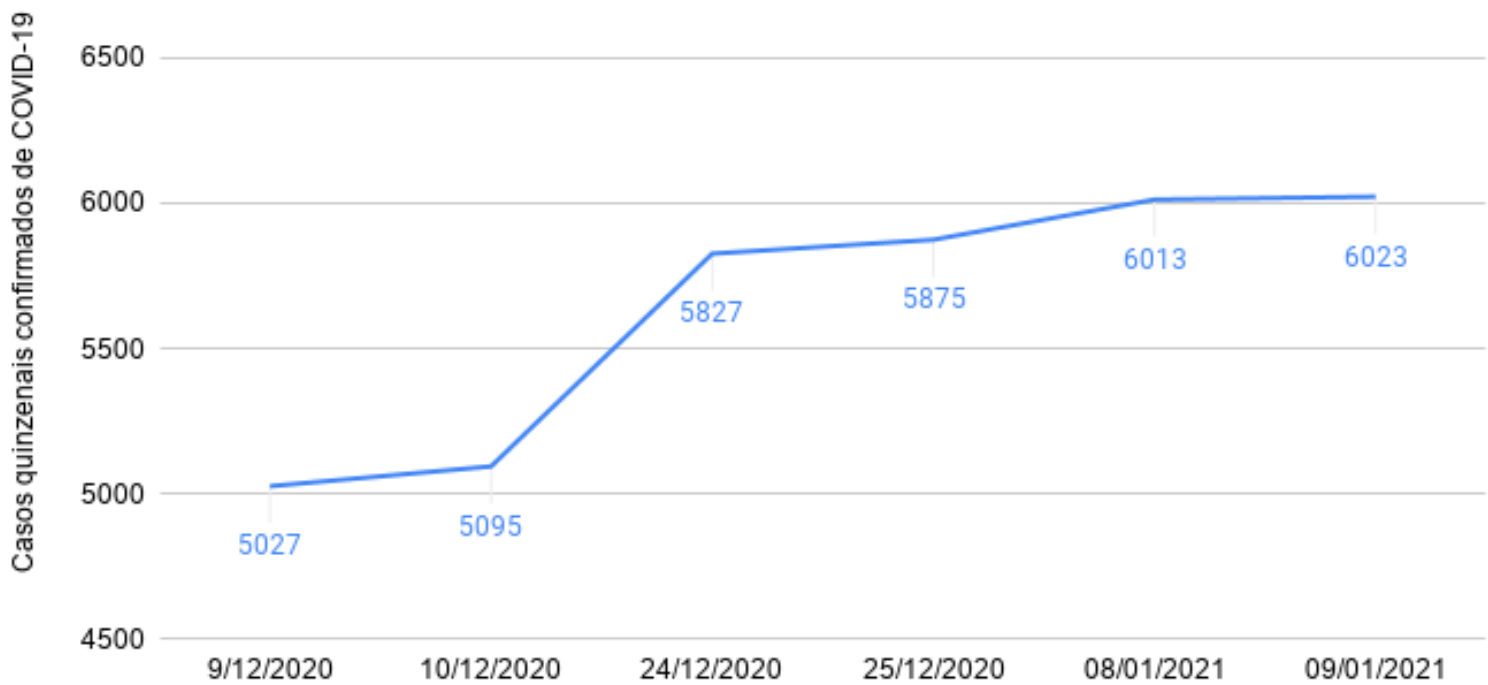


Fonte: Secretaria de Saúde de Jataí

Figura 7: Casos quinzenais confirmados de COVID-19 em Jataí-GO no período do Ano Novo. 7000

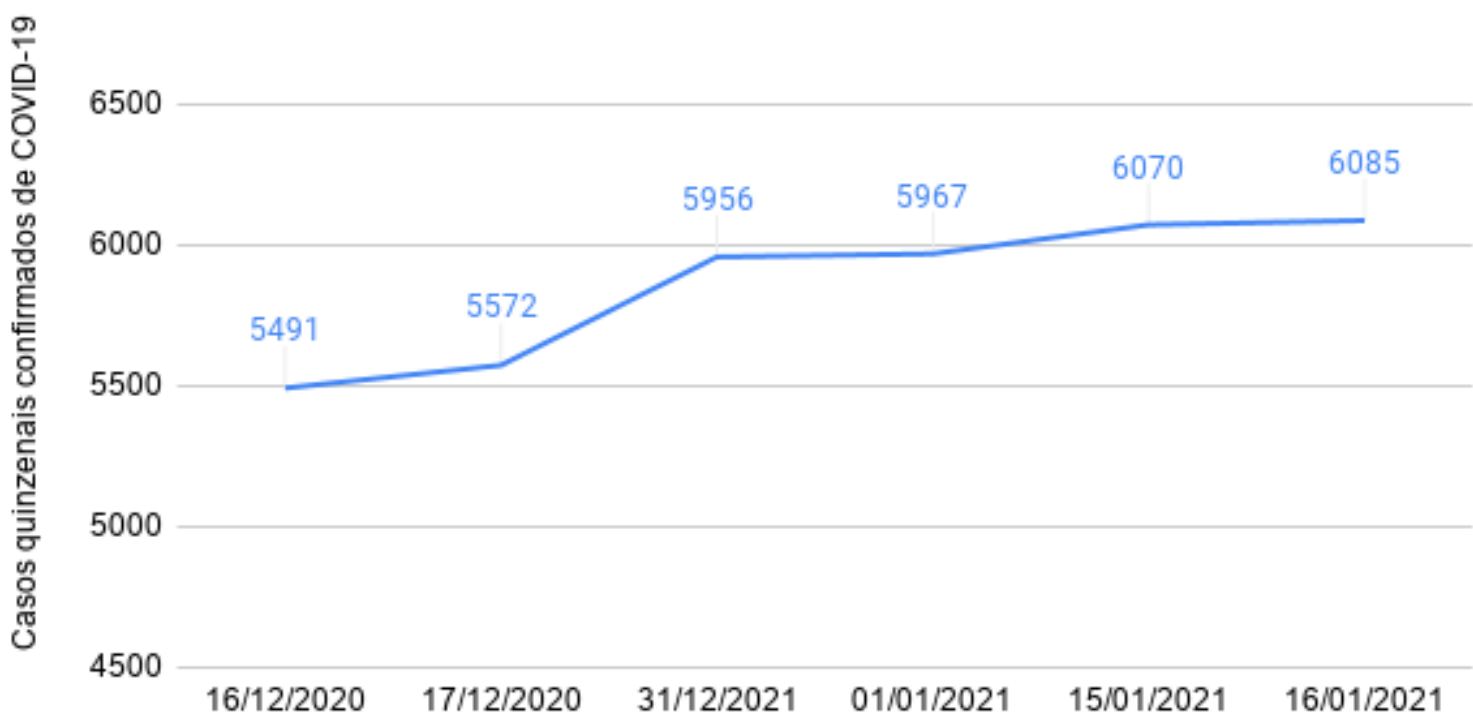

Fonte: Secretaria de Saúde de Jataí

Ao analisar as taxas de ocupação de enfermarias e de UTI, percebeu-se que estas acompanham o aumento e as quedas dos casos notificados. As menores taxas de ocupação foram observadas em 31 de outubro de 2020, com 35\% dos leitos de UTI ocupados (Figura 8). Ademais, em relação às taxas de ocupação de UTI, estas se mantiveram acima de $80 \%$ desde o início do ano de 2021, chegando a 100\% de ocupação nos 15 dias posteriores ao período de carnaval. 
Figura 8: Taxa de ocupação dos leitos de UTI em Jataí-GO de 31 de junho de 2020 a 15 de abril de 2021

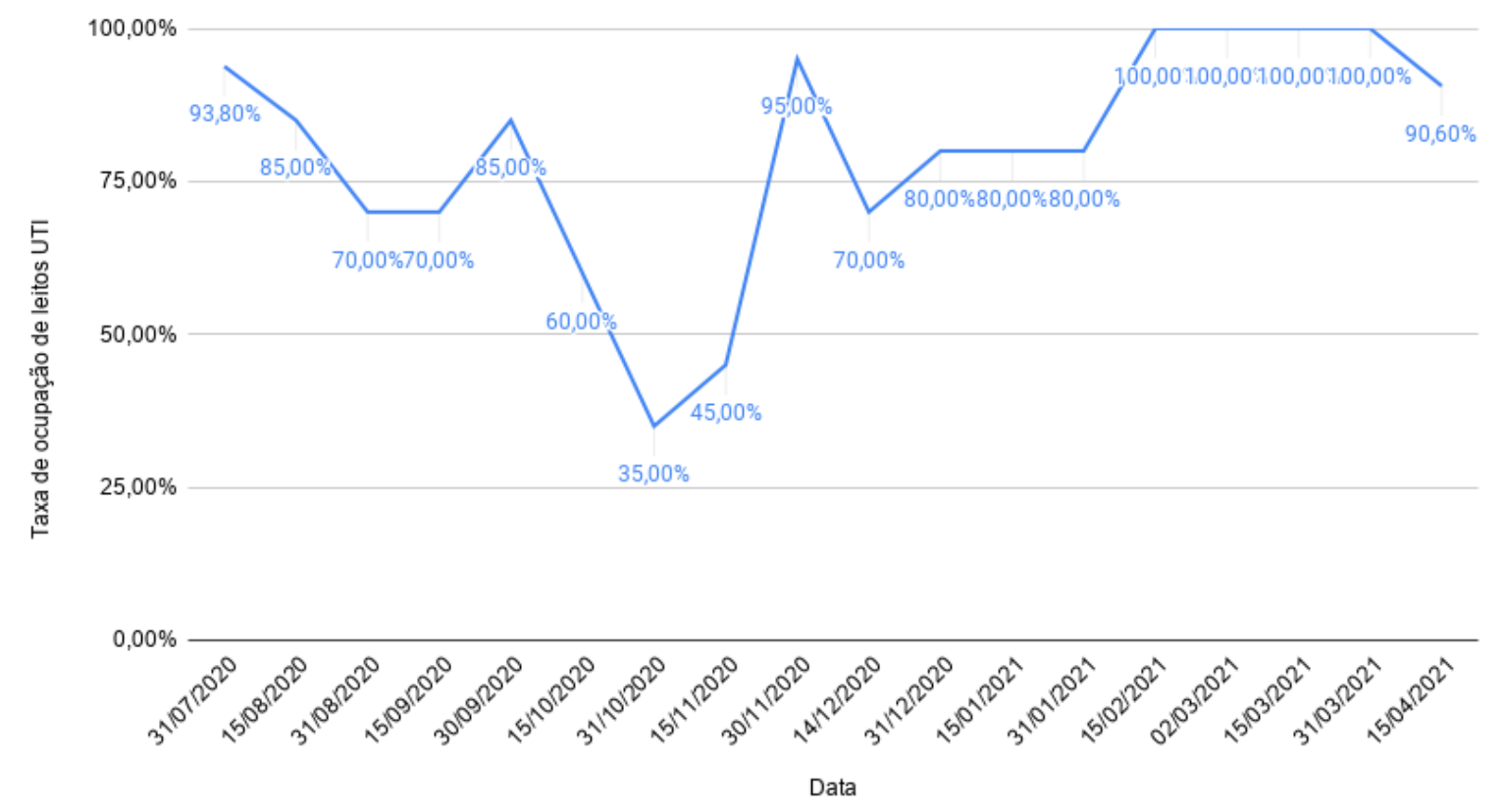

Fonte: Secretaria de Saúde de Jataí

O primeiro óbito por COVID-19 ocorreu no dia 29 de maio de 2020. Com relação à evolução dos óbitos durante a pandemia, observou -se que a taxa de mortalidade acompanhou os aumentos dos casos notificados (Figura 9). 
Figura 9: Óbitos quinzenais por COVID-19 em Jataí-GO de 18 de março de 2020 a 15 de abril de 2021.

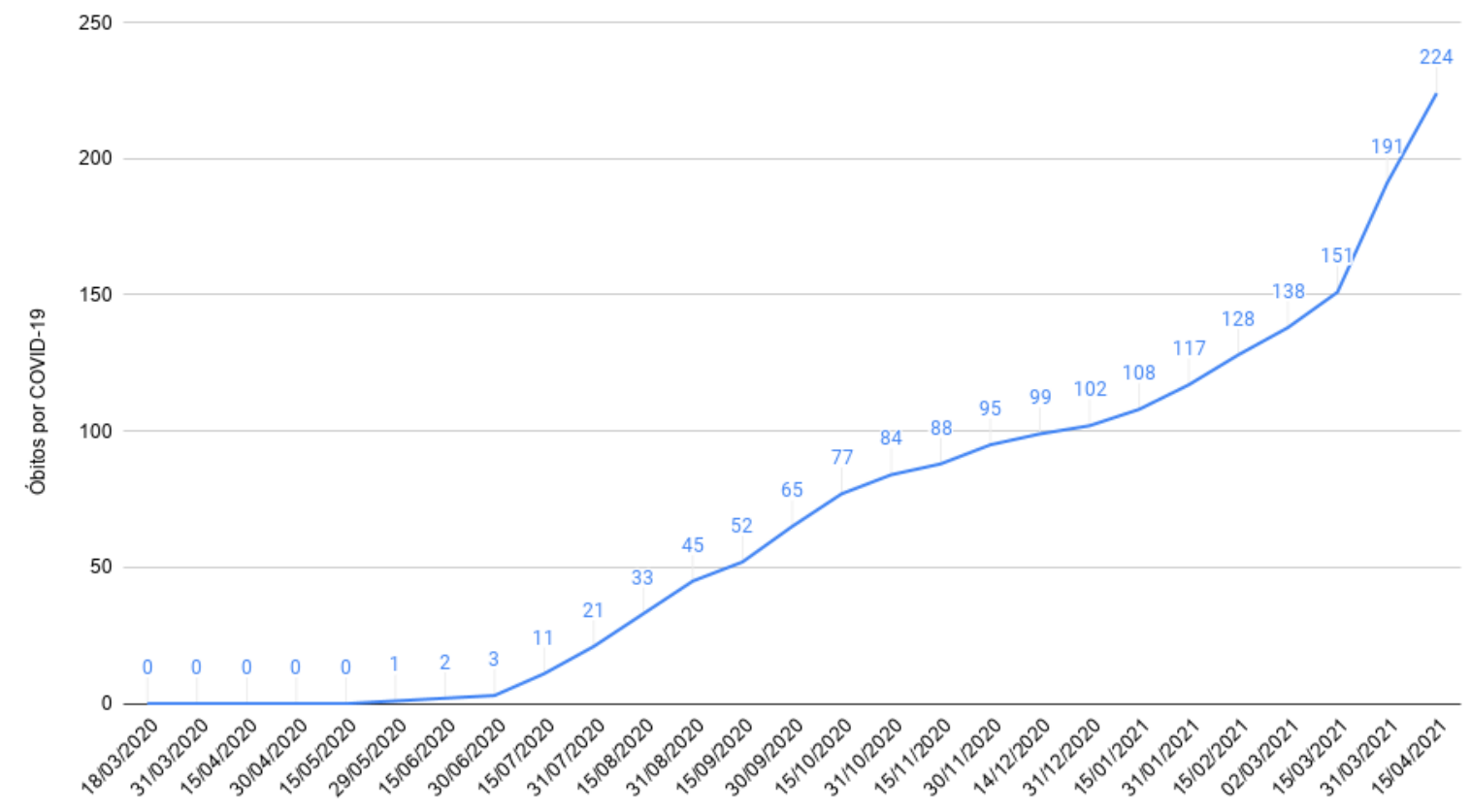

Fonte: Secretaria de Saúde de Jataí

Nesse sentido, notou-se, no município de Jataí, os reflexos das eleições e feriados no período da pandemia da COVID-19. A exemplo disso, estão as Eleições de 2020, em que o primeiro turno ocorreu no dia 15 novembro e o segundo turno no dia 29 de novembro. Desse modo, com base na pesquisa realizada no município, foi possível observar que houve um aumento considerável do número de indivíduos infectados após o período eleitoral.

Sendo assim, no dia 31 de outubro, quinze dias antes do primeiro dia de eleições, o município apresentava-se com 4.414 casos confirmados. Já no dia 15 de novembro, em que houve a realização do primeiro turno, foram contabilizados 4.598 casos confirmados. Ademais, no dia 30 de novembro, após quinze dias do primeiro turno de eleições, o município apresentou 4.853 casos confirmados (Figura 2).

Também pôde-se perceber que no feriado de Carnaval de 2021, o qual ocorreu no dia 16 de fevereiro, houve um aumento considerável do número de infectados. Nesse esteio, no dia 31 de janeiro, Jataí apresentava um total de 6.367 infectados. Outrossim, quinze dias após essa data, no dia 16 de fevereiro, feriado de Carnaval, o município registrou 6847 casos confirmados. Quinze dias após, no dia 2 de março, contabilizaram-se 7359 casos confirmados (Figura 3).

Vale citar que quinze dias anteriores aos feriados de Sexta-feira Santa de 2021, que ocorreu nos dias 01 e 02 de abril, e de Páscoa de 2021, o qual ocorreu no dia 4 de abril, o número de casos confirmados na cidade era de 8.179. Observando assim a alta até as datas 
desses feriados, nos dias 01 e 02 de abril, Jataí apresentava 9.130 e 9.149 casos confirmados, respectivamente, e no dia 04 foram contabilizados no município 9192 casos. Nessa linha, cerca de quinze dias após essas datas, houve um aumento significativo dos casos confirmados, sendo que foram confirmados 9.701 casos (Figura 10).

Figura 10: Casos quinzenais confirmados de COVID-19 em Jataí-GO no período do feriado de Páscoa, Jataí 2020-2021.

10500

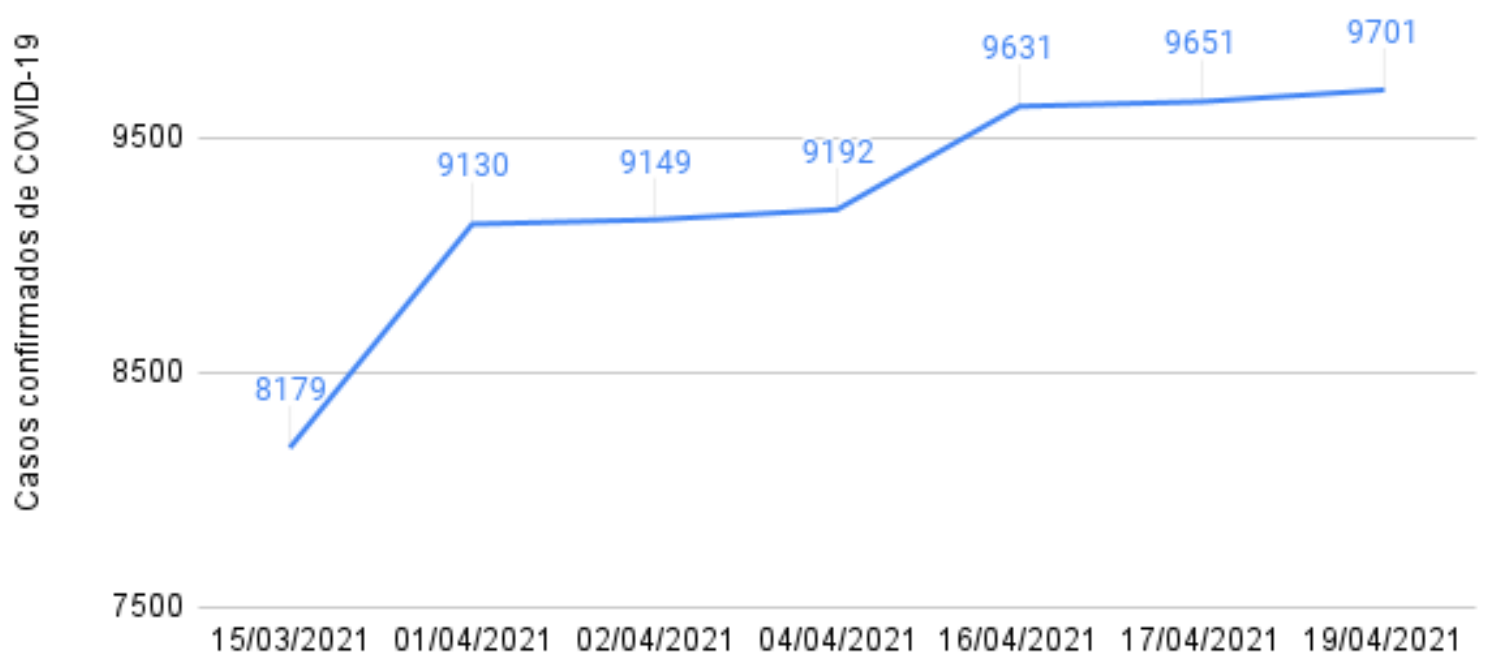

Fonte: Secretaria de Saúde de Jataí

\section{DISCUSSÃO}

O número de casos novos quinzenais da COVID-19 no município de Jataí apresentouse em alta desde o seu início em março de 2020, até a primeira quinzena do mês de agosto de mesmo ano, quando iniciou-se um período de queda. No entanto, esse período não se manteve estável nos meses seguintes, com períodos de instabilidade da curva, apresentando picos no período eleitoral até a primeira quinzena de janeiro de 2021. Conforme o esperado, foi então possível observar um cenário crescente desta epidemia em Jataí, conforme o esperado, relacionado com as datas comemorativas da cidade. Destaque deve ser dado ao período compreendido entre fevereiro e abril de 2021, no qual se observa aumento constante e com o maior pico da epidemia. 
As políticas de saúde adotadas em crises sanitárias, como a da COVID-19, bem como os procedimentos para sua implementação, são determinantes nos rumos adquiridos pela história natural da doença em cada Estado particular (AQUINO et al., 2020). No Brasil, decretos são publicados periodicamente para regulamentar as medidas de distanciamento social, evidentemente necessárias no atual cenário de disseminação do SARS-CoV-2. Todavia, a avaliação da eficácia de tais políticas faz-se necessária a fim de identificar problemas no estabelecimento das medidas de distanciamento, seja por incongruências em sua formulação ou por motivo da não adesão da sociedade. Por isso, a análise das determinações dos decretos municipais da Prefeitura de Jataí e a evolução da curva de casos de COVID-19 faz-se importante para determinar a assertividade da gestão do município em seu combate.

O distanciamento social pode ser considerado uma estratégia imprescindível para a redução da transmissão do vírus na ausência de vacinação ou tratamento (LEE, et al, 2021). Entretanto, percebe-se que existem dificuldades para o pleno exercício dessa estratégia, como exemplos estão os feriados e as eleições. Diante disso, estes são caracterizados por uma migração de massas, em que pessoas viajam e promovem reuniões que culminam em aglomerações, o que contribui para a disseminação do novo coronavírus (GUGLIELMI, 2020).

Isto posto, faz-se uma análise da curva de infecção no período de eleições, ocorrido em novembro de 2020. A elevação da curva 15 dias após o primeiro turno pode ser justificada pelas aglomerações promovidas pelo evento político. Todavia, é importante destacar que anteriormente, no dia 3 de novembro, a prefeitura municipal determinou, via Decreto $n^{\circ}$. 3.867 , a flexibilização das medidas de distanciamento social - como a permissão do retorno de servidores públicos do grupo de risco às atividades presenciais nas repartições públicas, a permissão de realização de eventos para até 150 pessoas, dentre outras flexibilizações que culminam com aglomerações. Por isso, pode-se pensar no impacto deste decreto nos números pós-eleições, haja visto que, como já demonstrado pelo Imperial College COVID-19 Response Team (2020), medidas brandas para a restrição da circulação de pessoas tendem a agravar a epidemia.

Com o agravamento da pandemia pela disseminação de novas variantes do vírus no início de 2021, a prefeitura instituiu lei seca, ao fim de janeiro, via Decreto $\mathrm{n}^{\circ}$. 0041, no qual o comércio estaria proibido de vender bebidas alcoólicas a partir das $22 \mathrm{~h} 00$. No dia 17 de fevereiro, após um acentuado aumento de casos de COVID-19 no município, foi publicado o Decreto $\mathrm{n}^{\circ}$. 0054, que restringiu a lotação em diversos estabelecimentos. Somente em primeiro de março foi decretado lockdown, a partir do Decreto $n^{\circ}$. 0057. Entre a publicação dos dois 
últimos decretos, mais de 50 casos foram notificados, sendo que cerca de $80 \%$ deles se deu duas semanas após o feriado de carnaval. A conduta da gestão municipal frente ao feriado se mostrou ineficaz uma vez que, ao prever intensa movimentação ocasionada pelo feriado, postergou a tomada de medidas rígidas para o distanciamento social.

No mesmo sentido, o Decreto $\mathrm{n}^{\circ}$. 0069, de 22 de março de 2021, instituiu medidas de restrição rigorosas, no entanto, vigente somente até o período anterior à semana santa e ao feriado de Páscoa. O resultado da abertura do comércio foi evidenciado pelo crescimento da curva de contágio também após cerca de duas semanas - que corresponde ao tempo médio de incubação do SARS-CoV-2 - dos referidos eventos. A relação estabelecida entre feriados e o período ao qual os decretos com rigoroso distanciamento social permanecem em vigência denotam claramente a prevalência de interesses do capital sobre políticas de saúde (TERRIS, 1980).

O retorno às atividades presenciais no contexto da pandemia da Covid-19 está diretamente relacionado à definição das medidas de proteção ao Sars-Cov-2 intituladas pelas instituições de saúde e governamentais a nível de cada país e até mesmo mundial. O cenário ideal priorizado pelo Comitê de Operações Estratégicas (COE) do Estado de Goiás para que atividades práticas possam ser viabilizadas, baseia-se em redução do número de óbitos por COVID-19 em 15\% ou mais e taxas de ocupação de leitos de UTI menores que $75 \%$, sendo que essas taxas devem ser sustentadas por 4 semanas epidemiológicas consecutivas. Espera-se então, um retorno de práticas presenciais do ensino superior, conforme preconizado pela Portaria MEC $\mathrm{N}^{\circ} 1038$, publicada em 7 de dezembro de 2020, pela Nota Técnica $\mathrm{N}^{\circ} 15 / 2020$ da SES - GO publicada em 29 de outubro de 2020 e Decreto No 3867 Prefeitura de Jataí publicado em 3 de novembro de 2020, assim que os indicadores definidos pelo COE sejam alcançados. Esses indicadores serão ainda monitorados e serão realizadas avaliações quinzenais para averiguar a compatibilidade do cenário de Jataí com o preconizado pelo COE.

Países como a Noruega, França, Dinamarca e Holanda estabeleceram normas de proteção a fim de que o retorno às atividades essenciais fosse restabelecido. Dessa forma, na Noruega medidas como redução de turmas, horário de funcionamento reduzido, distanciamento social, proibição de compartilhamento de lanches e proibição de brinquedos trazidos de casa proporcionaram à população norueguesa a retomada das aulas presenciais para que, consequentemente, a educação de inúmeras crianças e jovens não sofressem prejuízos de aprendizado oriundos do ensino remoto. Já na França, o retorno das atividades escolares presenciais ocorreu após um mês de fechamento das escolas, tendo como medidas protetivas e 
preventivas turmas reduzidas com no máximo 15 alunos por sala, ensino híbrido (metade da turma assiste às aulas presencialmente e outra parte assiste de maneira remota, de modo que aconteça um revezamento), retorno voluntário (os alunos poderiam optar pelo ensino a distância, caso não se encontrassem seguros de forma presencial), além do uso de máscaras, de álcool em geral e, não menos importante, o distanciamento social. (BERLADIM, Graziela. 2020).

Momentos como estes referidos de retomada do ensino presencial estavam vinculados com a queda no número de casos e mortes em decorrência da COVID-19. Em junho de 2020, quando estas medidas foram tomadas, a pandemia estava em uma fase controlada, como o presidente do conselho científico francês a classificou, ainda que já houvesse a suspeita de uma possível degradação crítica no cenário da pandemia no país (PRESSE, France. 2020).

Deve-se lembrar ainda que o Sistema de Informação de Agravos de Notificações (Sinan) foi desenvolvido a fim de registrar a coleta e processamento de dados sobre determinadas doenças, de modo com que sejam elaboradas informações suficientes sobre a morbidade e mortalidade de acometidos, para que assim fique a cargo dos municípios, estados e federação a tomada de decisões frente ao controle que a doença requer (LAGUARDIA, 2004). No caso da COVID-19, a notificação de casos suspeitos, casos confirmados e óbitos sugere às entidades responsáveis pelo controle endêmico da doença, interferências que resultem na maior cobertura vacinal, investimento em pesquisas científicas para tratamentos específicos, aumento de leitos que atenda m à demanda populacional, contratação de profissionais de saúde, elaboração de projetos de qualificação profissional e técnica e aquisição de suprimentos hospitalares suficientes (MASSUDA, 2020).

No cenário brasileiro atual de enfrentamento à COVID-19, o número de casos confirmados por critério clínico, clínico-epidemiológico, clínico-imagem, laboratorial e laboratorial assintomático (BRASIL, 2021) tem sido amplamente subnotificado, ainda que as notificações disponíveis se encontram em níveis exacerbados (PRADO, 2020). Além das subnotificações de casos confirmados, o que se tem também em relação a elaboração de notificações e dados sobre a COVID-19, são as mudanças que interferem na oscilação de números de casos e acometimento populacional, como o aumento no número de leitos de enfermaria e UTI das redes públicas e privadas.

\section{CONSIDERAÇÕES FINAIS}


Com presente estudo foi possível observar que a situação epidemiológica da COVID19 no município de Jataí ainda não se encontra em estabilidade, apresentando altas de casos, óbitos e ocupações de leitos diretamente relacionadas aos períodos de maior tendência a aglomerações, como datas comemorativas e período eleitoral aliada à baixa aderência da população às medidas de proteção e prevenção coletivas e individuais. Deve-se ressalvar que mudanças das notificações podem ter influência de possíveis mudanças adotadas nas notificações e/ou mudança da gestão. 


\section{REFERÊNCIAS BIBLIOGRÁFICAS}

AQUINO, E. M. L. et al. Medidas de distanciamento social no controle da pandemia de COVID-19: potenciais impactos e desafios no Brasil. Ciência \& Saúde Coletiva, v. 25, p. $2423-$ 2446, 2020.

BAI, Y.; YAO, L.; WEI, T. et al. Presumed Asymptomatic Carrier Transmission of COVID19. JAMA, 2020.

BERLADIM, Graziela. Retomada das aulas no mundo: veja as medidas que estão sendo tomadas pelas escolas que já reabriram em outros países. Clipe Escola. 2020.

BRASIL. Lei No 12.527, de 18 de novembro de 2011. Lei de Acesso à Informação. Presidência. Disponível em http://www.planalto.gov.br/ccivil_03/_ato2011- 2014/2011/lei/112527.htm, último acesso em 11 de novembro de 2020.

BRASIL. Ministério da Saúde. Definição de caso e notificação, 2021

CHAN, J.F.W.; YUAN, S.; KOK, K.H. et al. A familial cluster of pneumonia associated with the 2019 novel coronavirus indicating person-to-person transmission: a study of a family cluster. The Lancet, v. 395, p. 514-523 2020.

COMITÊ EXTRAORDINÁRIO DE MONITORAMENTO COVID-19. Boletim 02/2021. São Paulo: Associação Médica Brasileira. 23 de março de 2021.

FERGUSON, Neil et al. Relatório 9: Impacto das intervenções não farmacêuticas (INP) na redução da mortalidade por COVID19 e da demanda por saúde. Imperial College London, v. 10, n. 77482, p. 491-497, 2020.

GHINAI, I.; MCPHERSON, T.D.; HUNTER, J.C. et al. First known person-to-person transmission of severe acute respiratory syndrome coronavirus 2 (SARS-CoV-2) in the USA. The Lancet, 2020; : S0140673620306073.

GUGLIELMI, G. Coronavirus and public holidays: what the data say. Nature. 2020 Dec;588(7839):549. DOI: 10.1038/d41586-020-03545-1.

PREFEITURA MUNICIPAL DE JATAÍ. Boletim Epidemiológico sobre o Coronavírus em Jataí. 2020. Disponível em: https://www.jatai.go.gov.br/secretaria-da-saude/ 
PREFEITURA MUNICIPAL DE JATAÍ. Boletim Epidemiológico sobre o Coronavírus em Jataí. 2021. Disponível em: https://www.jatai.go.gov.br/secretaria-da-saude/

JATAÍ (Município). Decreto n ${ }^{\circ}$. 3.867, de 03 de novembro de 2020. Altera o Decreto ${ }^{\circ}$. 3.826 de 21 de setembro de 2020, e dá outras providências. Diário Oficial Eletrônico do Município de Jataí. Goiás, 2020.

JATAÍ (Município). Decreto ${ }^{\circ}$. 0041, de 27 de janeiro de 2021. Adota diretrizes do Governo do Estado de Goiás referente a medidas excepcionais de restrição ao comércio de bebidas alcoólicas no município de Jataí, e dá outras providencias. Diário Oficial Eletrônico do Município de Jataí. Goiás, 2021.

JATAÍ (Município). Decreto ${ }^{\circ}$. 0054, de 17 de fevereiro de 2021. Adota diretrizes do Governo do Estado de Goiás referente a medidas excepcionais de enfrentamento da pandemia do Coronavírus (COVID-19) no âmbito do Município de Jataí, e dá outras providencias. Diário Oficial Eletrônico do Município de Jataí. Goiás, 2021.

JATAÍ (Município). Decreto ${ }^{\circ}$. 0057, de 01 de março de 2021. Dispõe sobre suspensão total das atividades não essenciais e da circulação de pessoas e veículos particulares (lockdown), no âmbito do Município de Jataí, e dá outras providências. Diário Oficial Eletrônico do Município de Jataí. Goiás, 2021.

JUNIOR, Guanis et al. Aspectos epidemiológicos da COVID-19: uma revisão sistêmica. Piracicaba-SP: Revista CPAQV - Centro de Pesquisas Avançadas em Qualidade de Vida. Vol.12. No 2, 2020.

LAGUARDIA, Josué et al. Sistema de Informação e Agravos de Notificação (Sinan): desafios no desenvolvimento de um sistema de informação em saúde. Rio de Janeiro-RJ: Epidemiologia e Serviços de Saúde. Vol.13 Nº 3, 2004.

LEE, T.; KWON, H. D.; LEE J. O efeito das medidas de controle na transmissão de COVID19 na Coréia do Sul. 2021 PLoS ONE 16 (3):e0249262. https://doi.org/10.1371/journal.pone.0249262

MASSUDA, Adriano et al. A resiliência do Sistema Único de Saúde frente À COVID-19. São Paulo-SP: Fundação Getúlio Vargas, Artigo submetido em 24 de agosto de 2020 e aceito para publicação em 18 de dezembro de 2020 
NAVECA, F. et al. Phylogenetic relationship of Sars-CoV-2 sequences from Amazonas with emerging Brazilian variants harboring mutations E484K and N501Y in the Spike protein Update of the Sars-CoV-2 genomic surveillance in the Amazonas state, Brazil. Virological. 3 fev. 2021.

POZZEBOM, Fábio. Humanista: Jornalismo e Direitos Humanos. 2020.

PRADO, Marcelo et al. Análise da subnotificação de COVID-19 no Brasil. Rio de Janeiro: Revista Brasileira de Terapia Intensiva. 2020

PRESSE, France. Pandemia 'está controlada' na França, diz presidente do Conselho Científico. G1. 2020

SESGO. Secretaria Estadual de Saúde do Estado de Goiás. Atualização dos casos de doença pelo coronavírus (Covid-19) em Goiás (19/03/2020). Disponível em: <https://www.saude.go.gov.br/coronavirus/noticias-coronavirus/10593-atualizacao-dos-casosde-doenca-pelo-coronavirus-covid-19-em-goias-19-03-2020>. Acesso em: 27 abr. 2021.

TERRIS, Milton. Epidemiologia como guia da política de saúde. Revisão anual da saúde pública, v. 1, n. 1, pág. 323-344, 1980.

WHO. WORLD HEALTH ORGANIZATION. Coronavirus disease 2019 (COVID-19) Situation report - 57. 2020. Disponível em: <https://www.who.int/docs/defaultsource/coronaviruse/situation-reports/20200317-sitrep-57-covid-19.pdf?sfvrsn=a26922f2_4>. Acesso em: 14 abr. 2020. 